\title{
invenção da moda brasileira
}

\section{Luz García Neira $\boldsymbol{I}$}

Resumo: Esta argumentação toma como verdadeira a idéia de que existe, ou existiu, aquilo que pode ser chamado de "moda brasileira", não em função de sua origem produtiva, mas pela manifestação de uma estética que lhe é particular, ainda que seja no imaginário das pessoas. Investigando a procedência desse discurso, constata-se em sua base a presença de um ideal nacionalista estetizado em cores, formas e volumes próprios da gramática visual da moda, ainda carente de um estudo próprio, pois a "moda brasileira" tem sido abordada prioritariamente por meio de sua história ou da sociabilidade de seus signos, mas raramente em sua estrutura como linguagem. Este trabalho sugere modos de análise para este fenômeno.

Palavras-chave: moda brasileira; linguagem visual; sociabilidade

\begin{abstract}
This article considers true the idea that exists, or existed, what we might call "Brazilian fashion", not due to its productive origin, but, because of the manifestation of an aesthetics which is specific of it, even though it lies with the imagination of people. While investigating the origin of this statement, we noticed in its foundation the presence of an aesthetic nationalist ideal, with the use of colors, shapes and volumes which are peculiar to the visual grammar of fashion, this last one still lacking its own study. The "Brazilian fashion" has primarily been dealt with its history or with the sociability of their signs, but rarely had its structure studied as a language. This work suggests methods to analyse this phenomenon.
\end{abstract}

Licenciada em Artes Plásticas e Mestre em Ciências da Comunicação, é docente do curso de Bacharelado em Design de Moda do Centro Universitário SENAC-SP. E-mail: luz.nlaudisio@sp.senac.br 
O debate em torno da idéia de uma "moda brasileira" $\mathbf{2}$ é travado, como mínimo, desde os anos 20 do século passado quando as indústrias têxteis brasileiras nivelaram-se tecnicamente em relação às européias e às americanas, no sentido de capacitarem-se para a produção de tecidos concorrentes, o que supõe a produção de bens equivalentes com preço competitivo. Devido às características climáticas e culturais que nos diferem do sistema de criaçãoprodução-consumo de moda europeu, personalidades atuantes no setor, como os editores das revistas de moda e os dirigentes das indústrias têxteis, passaram a questionar implicitamente se deveríamos continuar a seguir, em termos de indumentária, as referências estéticas estrangeiras que chegavam até nós pelo cinema e pelas revistas e, além disso, também pelo amplo e legitimado discurso de bom gosto e elegância constituído na Europa e, alguns anos mais tarde, nos Estados Unidos da América.

A pesquisa histórica exploratória demonstra que essa insatisfação surgiu no seio da indústria têxtil (SILVA, 1989) e, portanto, tratou-se muito mais de uma ação que visava à proteção econômica do setor do que um pleito pelo direito à "expressividade" nacional por meio das roupas. Essa preocupação, no entanto, aconteceu em momento oportuno quando a defesa pela industrialização e pelo emprego alinhou-se com as preocupações da arte no período que, de modo mais evidente desde a Semana de 22, também buscava seu próprio caminho e se opunha aos modelos estrangeiros.

No período de instalação e desenvolvimento inicial das indústrias têxteis e do vestuário, destacaram-se ações comerciais em direção a uma pretensa "moda brasileira" por meio de um aprimoramento técnico que via a cópia como etapa inerente ao processo criativo. Um exemplo para comprovar essa prática diz respeito à Casa Canadá 3 que, desde os anos 1930, trazia roupas femininas diretamente de Paris e reproduzia duas ou três réplicas de cada modelo:

\footnotetext{
Mas nem tudo era copiado. Havia também criação local, inspirada nos modelos europeus, às vezes adaptados ao clima do Rio de Janeiro e do Brasil. Dona Mena já dizia, em junho de 1956, referindo-se à moda e à elegância da mulher brasileira que inspirar-se na França ou na Itália não quer dizer que não se tenha espírito criador. Sábios, cientistas, artistas e literatos não buscam sabedoria nos quatro cantos do mundo? (SEIXAS, 2001 p. 251)
}

2 No entender de Roland Barthes (2004, p.261), "todo sistema indumentário é regional ou internacional, nunca nacional”, o que poderia confrontar-se com a afirmação de uma "moda brasileira". Ocorre, no entanto, que se pressupõe a existência de uma estética precisa que assim pode ser denominada devido aos seus traços característicos e que foi elaborada prioritariamente a partir de uma visão estrangeira (midiática), ou seja, não é equivalente ao traje folclórico.

Funcionava no Rio de Janeiro até 1977 e fundada, possivelmente, em 1927. Foi o endereç

o do mais alto luxo em peles e roupas femininas no Brasil, tendo importado peças de estilistas famosos e, mais tarde, confeccionando cópias idênticas. Esse tipo de ação, no decorrer dos anos 1940 , era vista como incentivo à indústria nacional.

Esse tipo de atuação foi motivado por um desenvolvimento tecnológico interno que tornara o país preparado para a produção de têxteis. Ao não haver, no entanto, nenhuma trajetória cultural que adubasse a criação, não nos libertamos dos padrões da estética européia e, muito pelo contrário, ela se tornou referência absoluta quando avançamos na industrialização de têxteis e de roupas, notadamente a partir de 1920. A cópia adaptada climaticamente marcou o destino estético de praticamente todas as casas de prêt-à-porter que surgiram no período e ofereciam não só roupas, mas também um ambiente cenográfico (desfiles, concursos, campanhas publicitárias etc.), ideal para a solidificação desse comportamento, muito semelhante ao modelo europeu.

Em paralelo a esse tipo de atuação, no mesmo período, surge um dos primeiros exemplos de estetização alegórica do Brasil na forma de roupas, que é potencializado pelo sucesso no exterior: Carmem Miranda. Seu figurino, idealizado por Alceu Penna (1911-1980), levava as frutas e os balangandãs brasileiros para fora de nossas fronteiras, ajudando a criar midiaticamente uma idéia de estética tropical que coincidia com tudo aquilo que foi representação do Brasil desde o seu descobrimento. 


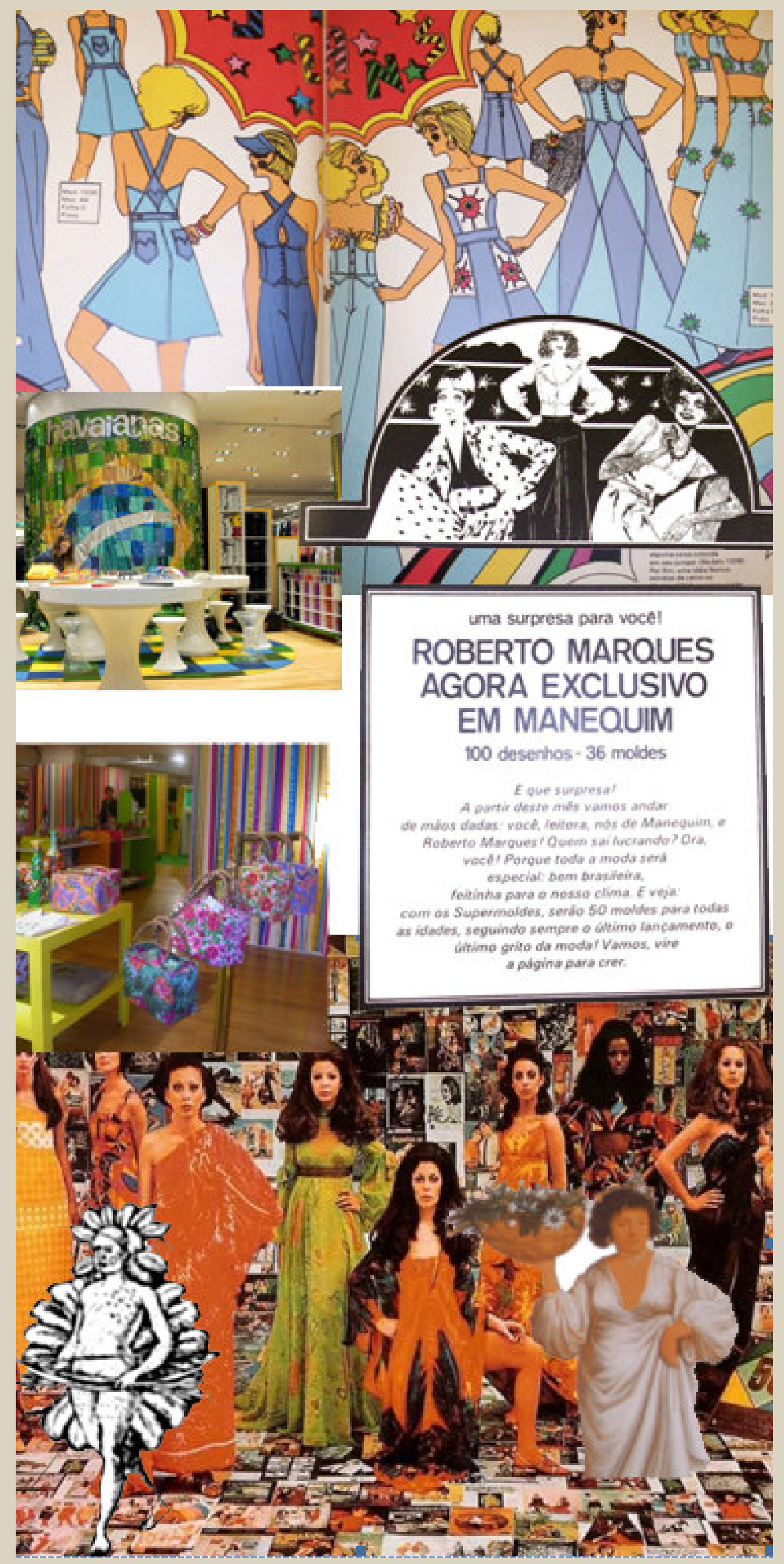

Fotomontagem de representações de moda brasileira: páginas dos anos 1970 da Revista Manequim (Ed. Abril), fotografia de criações da Rhodia, fotografias dos corners do Brasil nas Galerias Lafayete durante o Ano Brasil na França em 2005. Abaixo desenho de índio tupinambá no século XVI e de mameluca de Albert Eckout. 
Carmem Miranda, devido à sua posição de celebridade, ocupou e ainda ocupa ocasionalmente o papel de estética genuína em moda brasileira, mas não tem papel preponderante em este debate. $\bigcirc$ fato em análise está desvinculado de qualquer indivíduo, e parece ser justamente o ponto nevrálgico do confronto de idéias, pois dá indícios da presença na constituição da imagem visual da brasilidade, tanto de aspectos relacionados à estratégia empresarial e midiática que pretendiam fazer deslanchar a "moda brasileira", quanto da sua inserção no campo da arte, cujas ações pioneiras foram empreendidas por Pietro Maria Bardi. Em ambos os casos fala-se do período 1940-1970.

Em maio de 1952, Prof. Bardi, o então Diretor do Museu de Arte (atual MASP), endereçou carta ao Dr. Alberto Alves Lima, diretor da Casa Anglo Brasileira (Mappin), solicitando patrocínio para a realização de um evento que contribuísse para a constituição e o estímulo de uma "moda brasileira". Buscava, com essa iniciativa, o apoio técnico e em materiais para a realização de um desfile de roupas inteiramente idealizadas e confeccionadas dentro do próprio museu, que possuía uma seção "reservada ao estudo e à realização de modelos com a finalidade de permitir uma segura afirmação da moda brasileira” (BARDI, 1952).

Essa proposta em direção à invenção 4 da "moda brasileira" iniciou-se por um convite feito por Bardi aos artistas Sambonet, Caribé e Burle Marx para a criação de estampas e peças "com o propósito de incrementar o estudo e o desenvolvimento da moda" (BARDI, 1952b). Bardi pretendia demonstrar a possibilidade de revelar na moda aqui produzida "aspectos vivos da nossa cultura", além de "estimular a autonomia da nossa moda como expressão das reais necessidades populares", ainda que, como se sabe, a Mappin Store estava muito mais voltada para as mulheres de classe média e alta ou para a "mulher moderna" (BONADIO, 2005b).

A apresentação da coleção aconteceu em novembro de 1952. O desfile, apresentado por moças oriundas de uma escola de manequins que funcionava no próprio museu, trouxe à cena cinqüenta modelos de roupas cujos nomes relacionavam-se a cidades, animais, alimentos ou produtos brasileiros, como perequê, jacaré, ararauna, confetis, foguete, Iguaçu, fronteira e outros. Ainda que a acolhida dessa proposta tenha sido favorável por toda a imprensa que finalmente apontava "a democratização da moda" e a sua libertação dos padrões europeus, Bardi, anos mais tarde, declarou que o projeto "não deu certo" (BARDI, 2004), muito possivelmente porque ainda percebia que a moda continuou a guiar-se, em grande medida, por padrões estrangeiros.

As idéias de um país eternamente exótico também foram reformuladas (ou aproveitadas) no transcorrer dos anos 1960 pela empresa de fios sintéticos Rhodia, numa associação da arte brasileira à sua matéria prima. A empresa planejou uma ação de marketing integrada, na qual o fabricante desses fios custeava as publicidades das tecelagens que exibiam o selo da marca, expondo padrões de artistas e modelos criados por estilistas brasileiros. Em associação com a companhia aérea VARIG e a Revista Cruzeiro, a Rhodia levava as criações nacionais para serem desfiladas na Europa, nos Estados Unidos e até no Japão. As suas principais coleções anuais e artistas convidados foram:

- Em 1962: Brazilian Nature por Livio Abramo;

- Em 1963: Brazilian Look por Heitor dos Prazeres;

Segundo o Dicionário Houaiss, nvenção refere-se à capacidade criadora ou coisa imaginada que se dá como verdadeira e, ainda, toda invenção humana inédita que possa ser aproveitada industrialmente. É no conjunto destes sentidos a proposta do termo.

- Em 1964: Brazilian Style, Aldemir Martins;

- Em 1965: Brazilian Primitive por Isabel Pons;

- Em 1966: Brazilian Fashion Team por Hércules Barsotti;

- Em 1967: Brazilian Fashion Follies por Willy de Castro.

Além dessas criações, a empresa investiu em uma estratégia de marketing igualmente associada à produção cultural local. No final da década, a temática 
tropicalista foi mote para a organização em 1968 e em 1969 de shows-desfiles comandados por nossos tropicalistas, que promoviam a utilização dos fios sintéticos por meio da associação de artistas e estilistas brasileiros às indústrias têxteis (BONADIO, 2005).

A partir dos anos 1970, a idéia da "moda brasileira" traduzida somente em imagens adquire conotação quase folclórica. Mesmo no trabalho realizado por Zuzu Angel (1921-1976), verifica-se um vínculo de criação intrinsecamente relacionada com representações do país, quando se sabe que essa adjetivação é extremamente limitada por não levar em consideração, também, os processos de produção, comércio/ circulação e uso. Fazendo uso somente dos atributos estéticos, tornou-se possível produzir "moda brasileira" desde qualquer lugar do globo.

Desse modo, condenada a uma constituição que se restringiu quase unicamente à linguagem visual, continuamos presos (dados apurados em pesquisa exploratória que indicam que a moda brasileira é vista, por vezes, como produção da cultura popular), de modo mais evidente depois do tropicalismo, a ver a moda ou a temática autodenominada brasileira impregnada de signos alegóricos. Assim, durante um longo período, a idéia de "moda brasileira" resumiu-se à utilização de cores primárias e secundárias, traços simplificados de ferramentas artesanais que resgatam a representação da natureza tropical, adornos com sementes, contas, conchas, penas ou escamas $\boldsymbol{5}$.Também estão sempre presentes formas reveladoras curtas ou decotadas, esvoaçantes, entreabertas etc., com aspectos finalizadores do feito e acabados à mão, como amarrados, desfiados, tintos desuniformemente e assim por diante. Lembram-nos, constantemente, da nossa nudez indígena que deixou perplexos nossos "descobridores".

\section{A moda: linguagens}

5 Análise inicial elaborada para a undamentação do artigo, mas sem pretensão de ser tomada como final.

6

uma tarefa bastante complexa a dequação das terminologias nesse segmento. Vestuário, por vezes, pode significar apenas a disponibilidade de certo conjunto de elementos (calças, blusas, sapatos etc.), mas não necessariamente a sua seleção para um determinado uso. Por outro lado, a utilização do termo "moda", de alguma maneira, indicaria um posicionamento de um conjunto de elementos frente a uma diretriz estética (dentro ou fora de), o que também não seria o caso. Barthes (2004) utiliza o termo vestuário e, com isso, quer dizer a seleção individual ou coletiva e sua inserção no sistema da moda.

7 A partir desse momento, substituio termo vestuário por moda por acreditar que a palavra corresponda melhor ao propósito do debate. Barthes (2004), no entanto, pensa na moda como traje, como escolha pessoal. Neste artigo a moda é entendida como discurso.

Se é prioritariamente ao longo do século XIX, no Brasil e no mundo, que a roupa ocupa lugar de elemento de distinção é porque a ela foi atribuído um determinado valor distintivo não decorrente de seu custo produtivo, mas sim resultante do binômio demanda-sacrifício, tema esse amplamente estudado pela sociologia e que confere à moda, unicamente, o status de mercadoria.

Essa exposição de distinções, ao lidar fundamentalmente com as aparências, é tomada como uma manifestação artística orientada pela decisão de um segmento cultural dominante que tem o poder de ditar os valores e, inclusive, sua morte (BERGAMO, 2004), quando entende que se homogeneízam e, portanto, perdem o seu valor distintivo. Apesar de incorporar (mesmo sem perceber) contribuições da teoria da informação para justificar as transições próprias da natureza desse fenômeno, a visão determinista da moda, na condição de abordagem preferida pela sociologia, hesita em compreendê-la como uma linguagem visual e, portanto, sujeita também à organização discursiva. Uma importante tentativa de argumentação sobre essa tese foi construída por Roland Barthes (2004) ao explorar as semelhanças estruturais entre a moda e a linguagem.

Apontou o autor que tanto a linguagem como o vestuário $\mathbf{6}$ são assuntos que, simultaneamente, devem ser considerados em sua individualidade e institucionalização, isto é, em seu próprio sistema e na história. Essa correspondência permitiu-Ihe explorar a língua como indumentária (cada peça de roupa individualmente), a fala como traje (a escolha pessoal de cada indivíduo, que é o que Barthes associa à idéia de moda) e, ainda, o vestuário como linguagem (o uso geral, as ofertas, as disponibilidades e as seleções), possibilitando a percepção das potencialidades expressivas de cada nível e, portanto, identificar que a significação só pode ser explorada e atingida em sua plenitude no nível do vestuário $\mathbf{7}$. 
Para Barthes (2004), portanto, a troca social pela moda é decorrente de uma formação e oferta não voluntária (língua) e uma seleção individual (fala) para que, finalmente, se a efetive como linguagem, pois, neste caso o autor não toma a moda como uma bandeira idealista de qualquer discurso, o que deve ser percebido quando se identifica, esteticamente, aquilo que pretendemos denominar como "moda brasileira".

\section{Na contramåo da linguagem: a "moda brasileira"}

Diferentemente da língua como instituição social que nos é preexistente, quando nos referimos à idéia de "moda brasileira", a indumentária (como língua) torna-se uma produção cultural com construção premeditada, pois o senso comum não leva em conta os fatores de produção-circulação-consumo (e os valores/significados que lhes são correspondentes), mas apenas a estética daquilo que se apresenta. Logo, a indumentária "brasileira" (cada unidade de peça do vestuário) como objeto de estudos é codificação que funda uma linguagem visual específica (a união de recursos expressivos materiais nas peças individualmente ou em sua composição) que não se renova de acordo com as mediações sociais que se estabelecem no tempo e no espaço.

É possível afirmar que cada unidade de peças do vestuário reúne e suporta os códigos que determinam o que é e o que não é "moda brasileira". Assim, contrariando qualquer obviedade de que os significados são determinados na mediação dos signos e, ainda, de que haveria possibilidade de flexibilizar sua significação, o conceito de "moda brasileira" é resultante de características materiais bem específicas, tanto em sua forma modelada (a construção de cada peça) quanto em sua materialidade (tecidos e adornos). $O$ seu significado é dado a priori e sua seleção e o seu uso social pelos indivíduos pode pretender apenas confirmá-lo ou refutá-lo, mas dificilmente reconstruí-lo.

Assim, as formas que a indumentária (língua) categorizada como "moda brasileira" adquiriu para representar os conceitos de brasilidade desejados, é o resultado de uma série de processos de atribuição de formas visuais aos discursos de nacionalidade em nosso caso particular, pois, como se sabe, os conceitos de nacionalidade são diferentes em cada lugar. Esse fato, ao opor-se novamente à idéia de Barthes (2004) que afirma que a moda nunca pode ser nacional, demonstra que a "moda brasileira" ocupa lugar de fato folclórico (conhecimento ou prática coletivizada instituída e dinâmica pela sua manutenção), ou seja, com significados pontuados que pretendem ser conservados. Isso, de certo modo, faz com que os significados dessa estética sejam determinados de modo rígido e, portanto, não abertos às atualizações conceituais das quais a moda globalizada se alimenta.

As hipóteses fundamentais que norteiam este debate - mas que ainda devem ser comprovadas por meio de estudo mais aprofundado -, entendem que o conceito de "moda brasileira" pretendeu alinhar-se às descrições estrangeiras que dominaram os relatos verbais ou visuais sobre o Brasil entre os séculos XVI e XIX e que, em contrapartida, também serviram para despertar o espírito de nacionalidade em nossos artistas e literatos. Assim, pretende-se sugerir inicialmente que:

- A linguagem visual da "moda brasileira" que se desenvolveu no período 1940-1975 é pautada em uma estética própria relacionada aos recursos naturais brasileiros e às manifestações da cultura popular;

- Esse conceito de "moda brasileira" tem relação com as manifestações artísticas que também pregam o nacionalismo na arte;

- Por se remeter a referências fixas (flora, fauna, clima, habitante aborígine etc.), o conceito de "moda brasileira" não se transformou em sentido lingüístico, o que a circunscreveu a alguns segmentos (como a moda-praia) e a localizou 
no tempo-espaço. Isso impede que, assim como a moda européia ou norteamericana, se evidenciem as características próprias do fenômeno da moda, como a temporalidade, a sazonalidade etc:;

- Essa "fixação referencial" constrangeu o desenvolvimento de uma moda globalizada, inserida no sistema de design industrial.

\section{Como analisar a "moda brasileira" do ponto de vista da linguagem?}

De acordo com as postulações anteriores, faz-se necessário inverter o processo de análise sugerido por Barthes (2004), partindo daquilo que a sociedade em geral toma como "moda brasileira" com significação dada a priori para, em seguida, compreender que visualidade é capaz de adquirir dita conotação. Só então seria possível compreender quais visualidades são capazes de incorporar tais conceitos e comprovar ou refutar a idéia inicial de que ainda estamos relacionados às primeiras descrições estrangeiras do Brasil, conforme tabela a seguir:

\begin{tabular}{|c|c|c|}
\hline MODA & TRAJE & INDUMENTÁRIA \\
\hline $\begin{array}{c}\text { A DISPONIBILIZACCÃO } \\
\text { EM OBJETOS E EM } \\
\text { DISCURSOS }\end{array}$ & $\begin{array}{c}\text { A SOMA DAS PECAS } \\
\text { EM SEU USO } \\
\text { INDIVIDUAL }\end{array}$ & $\begin{array}{l}\text { CADA UMA DAS } \\
\text { PECAS } \\
\text { SEPARADAMENTE }\end{array}$ \\
\hline A SOCIEDADE & $\begin{array}{c}\text { O INDIVÍDUO } \\
\text { O QUE INDICAM }\end{array}$ & A INSTITUIÇĀO 8 \\
\hline $\begin{array}{l}\text { O que a sociedade } \\
\text { nomeia e identifica } \\
\text { como moda brasileira }\end{array}$ & $\begin{array}{l}\text { Possíveis usos pelos } \\
\text { indivíduos }\end{array}$ & $\begin{array}{c}\text { Formas produzidas e } \\
\text { oferecidas para o } \\
\text { consumo }\end{array}$ \\
\hline \multicolumn{2}{|c|}{$\begin{array}{c}\text { A SER AI ALISADO } \\
\text { TOMANDO CS DISCURSOS }\end{array}$} & $\begin{array}{c}\text { A SER ANALISADO } \\
\text { A PARTIR DOS OBIETOS }\end{array}$ \\
\hline $\begin{array}{c}\text { O que o discurso } \\
\text { social (arte, academia, } \\
\text { mídia, indivíduos, } \\
\text { organizações etc.) } \\
\text { oferece ao debate na } \\
\text { qualidade de "moda } \\
\text { brasileira", tanto o que } \\
\text { lhe pertence, como o } \\
\text { que se entende como } \\
\text { falta. }\end{array}$ & $\begin{array}{l}\text { O que é reconhecido } \\
\text { como "moda brasileira" } \\
\text { (a visão nacional e } \\
\text { estrangeira); a questão } \\
\text { contemporânea; a } \\
\text { questão folclórica. }\end{array}$ & $\begin{array}{l}\text { Quais os elementos } \\
\text { visuais (formas, } \\
\text { volumes, cores, texturas } \\
\text { etc.) são propostos } \\
\text { pelas empresas, mídias } \\
\text { ou sujeitos legitimados } \\
\text { para a emissão de } \\
\text { discursos sobre a moda }\end{array}$ \\
\hline
\end{tabular}

Evidentemente, tanto a materialidade quanto a modelagem da indumentária, muito embora possam existir em grande quantidade e em inúmeras combinações, se repetem em diferentes pontos geográficos e momentos históricos (o que é chamado de caráter cíclico ou espiralado, a depender do autor), de maneira que roupa se tornam um dos grandes desafios dessa área de estudos. Ainda que 
fosse possível decifrar todos os modos de sua codificação, qualquer investigação poderia pretender abarcar somente um determinado tempo-espaço.

Os significados que as roupas em seu uso social adquirem - o nível discursivo - têm sido investigados muitas vezes a partir do deslocamento do estudo da visualidade do objeto para a sua apropriação, ou seja, exatamente no mesmo percurso em que Barthes (2004) identifica seu funcionamento: 1) a língua; 2) a fala; e 3) a linguagem, e que acaba por atribuir, à linguagem, papel preponderante sobre a designação de significados às roupas. Essa abordagem, apesar de possibilitar a verificação da constante negociação social das significações (sempre em mutação) e a visão da moda como uma experiência capaz de materializar as trocas sociais e não somente espelhá-las, parece insuficiente para explicar a criação dos sistemas de códigos visuais que articulam trocas.

Entende-se, a partir da pesquisa exploratória, que o discurso da "moda brasileira" tornou-se mais divulgado a partir dos anos 1950 (coincidindo, obviamente, com a ampliação da ação dos meios de comunicação de massa e, de modo especial, a televisão) devido à pretensão de apresentar ao mundo a nossa capacidade criativa com base na cultura local. A visualidade que a ele se associou acabou por afirmar algumas especificidades que possibilitam sua distinção imediata de "outras modas" (como as européias ou orientais, por exemplo), mas que, na verdade, está vinculada a discursos não relativos à moda (ou eminentemente estéticos), mas que se define pelo lugar ocupado pelo país. A visualidade gerada e tomada como "moda brasileira" parece ser compartilhada tanto por brasileiros quanto por estrangeiros.

O que interessa, no entanto, não é compreender como uma sociabilidade específica adquire determinada visualidade, mas, ao contrário, investigar como as visualidades podem ser consideradas "objetos significantes" (GREIMAS et al., 1989) dessa mesma sociabilidade. Transfiro minha atenção do modo de interpretar para o modo de representar a "moda brasileira".

Assim, o que cabe ainda analisar é um conjunto de formas que tem em comum traços materiais e modelares. A sua observação prevê a produção de associações entre a sua visualidade e um determinado corpo de significados previamente estabelecido, e não a busca de referentes específicos naquilo que Greimas (1989) chama de "mundo natural". Estima-se a compreensão dessa visualidade não por meio da leitura individual de cada elemento isoladamente (forma, cor, volume etc.), mas por sua expressividade, que a transforma em uma "figura de expressão", no entender de Louis Hjlmslev (1974), e possibilita como metodologia de pesquisa a análise da figuratividade de suas formas visuais.

Se deve ser considerado, no entender de Greimas (1989), que nossos processos de interpretação são conduzidos por algo generalizado e regular que compõe o significante em questão, é porque esse mesmo significante possui um significado independente de seu uso em uma determinada situação. Assim, no momento da produção de sentido, o que fazemos é comparar e contrastar um determinado sistema de símbolos a um sistema de significados, de onde se propõe uma semiótica semi-simbólica que atua, prioritariamente, entre dois níveis de linguagem, diferentemente dos sistemas simbólicos que procuram a correspondência entre planos de conteúdo e de expressão ou, ainda, nos sistemas semióticos onde essa correspondência não existe ( $F L O C H, 1985)$.

Daquilo que podemos entender como conteúdo de uma "moda brasileira" e que pode originar-se a partir de uma seleção inicial (como a que as fotografias da Galeria Lafayette resumem) é possível estabelecer categorias semânticas (apenas com função referencial) que se dirigem a, no entender de Hjlmslev (1974), a determinada expressividade (função poética). Esta, em termos de linguagem visual, 
pode ser analisada de acordo com os estatutos da própria geração/transporte e armazenamento de imagens.

\begin{tabular}{|c|c|c|}
\hline CONTEÚDO & \multicolumn{2}{|c|}{ EXPRESSÃO } \\
\hline $\begin{array}{c}\text { NÍVEL } \\
\text { FUNDAMENTAL } \\
\text { Determinação de } \\
\text { oposições semânticas } \\
\text { elementares } \\
\text { NÍVEL NARRATIVO } \\
\text { Efetivação de valores } \\
\text { pelos sujeitos } \\
\text { NÍVEL DISCURSIVO } \\
\text { Mecanismos de } \\
\text { instauração }\end{array}$ & $\begin{array}{c}\text { Modelagem: } \\
\text { Tipo de peça } \\
\text { Silhueta } \\
\text { Comprimento } \\
\text { Volume } \\
\text { Fechamento } \\
\text { Materiais e } \\
\text { materialidades: } \\
\text { Matéria-prima (quando } \\
\text { houver referência) } \\
\text { Estamparia e/ou } \\
\text { tingimento }\end{array}$ & $\begin{array}{c}\text { Análise de } \\
\text { níveis: representação, } \\
\text { abstração, simbolismo } \\
\text { Análise de geração } \\
\text { de imagens: pré- } \\
\text { fotográficas; } \\
\text { fotográficas; pós- } \\
\text { fotográficas } \\
\text { Análise de } \\
\text { composiçăo: } \\
\text { harmonia e contraste } \\
\text { (forma, escala, cor) }\end{array}$ \\
\hline
\end{tabular}

Dado que a visualidade da moda não pode ser analisada pela soma de suas partes (a matéria + o comprimento + a cor, por exemplo), a sua fragmentação pode conduzir à compreensão mais precisa da articulação de discursos. Ainda que este não seja um procedimento que possa ser definido completamente a priori, algumas teorias de estudos das composições visuais bem como das imagens, contribuem para esta análise.

\section{Consideraçōes finais}

Os fatos visuais, como a moda em seu aspecto estético, são um "fato social completo" no entender de Barthes (2004, p. 275) devido à sua função significante, que só é possível, obviamente, devido às trocas sociais que as linguagens possibilitam.

Tomando como premissa a necessidade de se estabelecer uma dada sociabilidade (objeto de estudo da moda-mercadoria), a análise da "moda brasileira", estimada a priori, só pode ter sua compreensão mais aprofundada a partir da contribuição de teorias lingüísticas, que poderiam explicar a ação da própria imagem como enunciadora e, portanto, como sujeito da ação discursiva. Nas palavras de Ulpiano Menezes (2005) "....] a Semiótica não pode neutralizar ou enfraquecer o fato, tão importante para a História, de que a imagem, além de signo, também age, executa o papel de ator social, produz efeitos" (p. 48).

É de responsabilidade dos processos semi-simbólicos, portanto, a fundação de uma "moda brasileira" cuja reverberação é evidente no campo econômico ou social. No primeiro, relacionam-se, com a estrutura empresarial, as questões trabalhistas, os aspectos econômicos das riquezas geradas por essa indústria etc.; e no segundo, com os padrões de status, elegância, gênero, classe e tantos outros que o fenômeno da moda permite visualizar.

A partir do aprofundamento de teorias lingüísticas, pode-se determinar quais auxiliarão no estudo do problema instaurado. Esta proposta parte de uma 
constatação sobre fatos de linguagem (a visualidade da "moda brasileira") que outras ciências analisam como fatos dados. É na sua construção, cujas lacunas ainda são enormes, que as ciências da linguagem dariam sua grande contribuição.

\section{Referências bibliográficas}

BARDI, P. M. [Carta] 6 mai. 1952, São Paulo [para] Dr. Alberto Alves Lima, São Paulo, 1 p. Solicita apoio para a realização de evento sobre moda brasileira.

- [Carta] sd out. 1952b, São Paulo [para] diversos convidados, 1 p. Convida para o desfile Moda Brasileira a se realizar em 6 de novembro de 1952 e explica a fundamentação do projeto.

40 anos de MASP. São Paulo: Crefisul, 1986.

BARTHES, R. Inéditos. São Paulo: Martins Fontes, 2004.

BERGAMO, A. Elegância e atitude: diferenças sociais e de gênero no mundo da moda. Cadernos Pagu, Dossiê: o gênero da moda e outros gêneros, n ${ }^{\circ}$ 22, Campinas, Janeiro-junho/2004. Disponível em http://www.scielo.br/ scielo.php?pid=S0104-83332004000100005\&script=sci_arttext. Acesso em 10 de janeiro de 2008.

BONADIO, M. C. O fio sintético é um show! Moda, política e publicidade; Rhodia 1960- 1970. Tese de Doutoramento em História. Campinas: UNICAMP, 2005.

Moda e sociabilidade. Mulheres e consumo na São Paulo dos anos 1920. São Paulo: SENAC, 2005b.

DONDIS, D. A. Sintaxe da linguagem visual. São Paulo: Martins Fontes, 2000.

DURAND, J. C. Moda, luxo e economia. São Paulo: Babel Cultural, 1988.

$\mathrm{FLOCH}$, J. M. Petites mythologies de l'oeil et de l’esprit. Por une sémiotique plastique. Paris: Editions Hadès-Benjamins, 1985.

GONTIJO, S., \& CÂMARA, J. 80 anos de moda no Brasil. Rio de Janeiro: Nova Fronteira, [1980].

GREIMAS, A. J., COLLINS, F., \& PERRON, P. Figurative semiotics and the semiotics of the plastic arts. New Literary History , 20 (3, Greimassian Semiotics), 1989, pp. 627-649.

HJELMSLEV, L. Prolegómenos a una teoría del lenguaje. Madrid: Editorial Gredos, 1974.

KRISTEVA, J. História da linguagem. Lisboa: Edições 70, 1974.

LOPES, P. E. Desinvenção do som: leituras dialógicas do tropicalismo. Tese de Doutoramento em Lingüística. São Paulo: FFLCH-USP, 1996.

MALERONKA, W. Fazer roupa virou moda. Um figurino de ocupção da mulher (São Paulo 1920-1950). São Paulo: SENAC, 2007. 
MENEZES, U. B. Rumo a uma "história visual”. In: J. d. MARTINS, C. ECKERT, \& S. C. NOVAES, O imaginário e o poético nas ciências sociais. Bauru, SP: EDUSC, 2005, pp. 33-56.

SILVA, G. A. Bangu 100 ano, a fábrica e o bairro. Rio de Janeiro: Sabiá Produções Artísticas, 1989.

SOUZA, G. R. A moda no século XIX. Ensaio de sociologia estética. Tese de Doutoramento em Sociologia . São Paulo: FFLCH-USP, 1950.

ZUZU ANGEL. Direção: Sérgio Rezende. Intérprete: Patrícia Pillar e outros. Warner Bros, 2006. 1 filme (103 min.). 